\title{
A Low-Cost Transcutaneous Electrical Nerve Stimulation Measuring Device Using Frequency-to- Voltage and Current-to-Voltage
}

\author{
Alfita Kurniawati”, Torib Hamzah, Tri Bowo Indrato \\ Medical Electronic Engineering Department, Poltekkes Kemenkes Surabaya \\ Jl. Pucang Jajar Timur No. 10, Surabaya, 60282, Indonesia
}

\section{Article Info}

Article History:

Received May 19, 2020

Revised July 14, 2020

Accepted July 21, 2020

Keywords:

TENS Device

Frequency-to-Voltage

Current-to-Voltage

Stimulation

\section{Abstract}

The use of transcutaneous electrical nerve stimulation (TENS) therapeutic devices to reduce the complexity of the patients continuing can cause an increase in the performance of the tool. The purpose of this study is to design a tool to calibrate TENS. The contribution of this study is the ease of users when performing TENS calibration because it can display the shape of the signal, the frequency value in units of $\mathrm{Hz}$, as well as the current value in units of $\mathrm{mA}$ directly. To match the frequency and current according to the position of the red electrode cable, it must be higher than the position of the black electrode cable. The frequency-to-voltage that is changed then entered is converted into a voltage to be processed using Arduino. Then also with the current-to-voltage, which changes the inrush current and then is converted into a voltage to be processed using Arduino. The results showed that the frequency values in all settings had an average error of 0.018 , while the average error of the current in all settings was 0.25 . At the frequency, a measurement obtained highest uncertainty value of $\mathrm{UA}$ is 1.6, UB is 0 , and the highest $\mathrm{U} 95$ is 6.88 while in the current measurement obtained, the highest uncertainty value of $\mathrm{UA}$ is 0.19 , UB is 0 , and highest $\mathrm{U} 95$ is 0.392 . The results of this study can be applied to the field of calibration, specifically the TENS therapy instrument calibration.
\end{abstract}

\section{Corresponding author:}

toribhamzah@yahoo.co.id

Medical Electronic Engineering Department,

Poltekkes Kemenkes Surabaya, Indonesia
This work is an open-access article and licensed under a CreativeCommonsAttribution-ShareAlike 4.0 International License(CC BY-SA 4.0).

\section{INTRODUCTION}

Electro-stimulator or TENS (Transcutaneous Electrical Nerve Stimulation) is one of the inexpensive therapeutic equipment that serves to relieve pain in non-invasive and nonpharmacological [1][2][3]. TENS activates complex neural networks to be able to reduce or even relieve pain without the influence of chemical drugs and activate the system of inhibitory systems in the central nervous system to reduce excessive pain [4]. TENS is thought to reduce pain by exceeding pain input and stimulating endorphins. TENS classified as a class II device and in 1972 has been approved by the FDA [5]. Although it conducts electricity to the human body, TENS is safe to use because the human body has resistance to the flow of electric current. More than $99 \%$ of the immune system is in the skin [6]. Everyone has different skin resistance. Dry skin resistance is generally between $1000 \Omega$ -
$100,000 \Omega$ [7]. But the use of TENS therapy to continuously reduce the pain intensity of patients can lead to concerns about reduced equipment performance. Therefore, TENS needs to be calibrated periodically so that the output corresponds to the mode options so as not to harm the patient. Based on the Regulation of the Minister of Health of the Republic of Indonesia Number 54 Year 2015 concerning testing and calibration of medical devices CHAPTER I Section 1, what is meant by calibration is an illumination activity to determine the correctness of the value of the appointment of measuring instruments and/or measuring materials. The parameters to note on TENS are the frequency and intensity of the signal [8]. Generally TENS is calibrated using an oscilloscope [9][10]. The use of the oscilloscope has a deficiency that is unable to display the current value directly. The voltage (amplitude) on the oscilloscope is then converted to $\mathrm{mA}$ to determine the pulse intensity. 
In 2015, Purwowibowo and Jalu Ahmad Prakosa conducted a study titled "Meter Frequency Prototype measuring range $(10 \sim 2000) \mathrm{Hz}$ Calibration to primary frequency standard, the results of this study stated that on 33 $\mathrm{Hz}$ measurements there was an error [11]. In 2017, Li Su et al. researched the title Design and Implementation of High Precision Digital Frequency Meter Based on C8051F020 Microcontroller. The results of the study had a small error value; however, the research using C8051F020 did not yet have many references [12]. In 2018, Abdul Adhiem et al. conducted a digital ammeter-based electromagnetic induction method; the results show that the appliance was not good if used to measure electrical current under $10 \mathrm{~mA}$; however, it is good if used to measure electrical current above 10mA [13]. In 2016, Yasin Kabalci and Ersan Kabalci researched low-cost voltage and current-voltage measurement devices. The study was designed to obtain a low-cost current measuring instrument, had high accuracy, and used a lower power supply; however, the components used did not have many references [14]. In 2011, Budi Prijo Sembodo researched Ampere Meter DC using ADC 0804 as an Interface to the computer central processing unit (CPU), this study can only measure current with a measuring limit of $50 \mu \mathrm{A} ; 2.5 \mathrm{~mA} ; 25$ $\mathrm{mA}$; and 0.25 A [15].

Based on the weaknesses and limitations that have been mentioned by previous researchers, among others, there are errors, narrow measurements, and lack of references. Therefore in this study will be designed TENS measurement device to view the shape of the signal, measuring the high frequency, and current on TENS. The uses of this design are more effective because it has advantages in terms of user friendly, which can display the current value directly.

This article consists of 5 parts; Part II contains methods and development conducted, Part III is the results obtained in this research, Part IV is the discussion of the findings, and Part $\mathrm{V}$ is the conclusion.

\section{MATERIALS AND METHODS}

\section{A. Experimental Setup}

This study uses three types of TENS to retrieve data. Data retrieval at a frequency carried out three times while data retrieval at current is taken one time.

\section{B. Materials and Device}

This study uses IC LM2917 (USA) in a frequency-tovoltage circuit. IC LM741 (USA) in summing amplifier, inverting amplifier, and current-to-voltage circuit. The microcontroller used to processing data (Arduino Uno, R3, Italy) and using software Arduino (Version 1.8.5, Italy). TFT LCD is used as a display (Nextion 2.4 inch, Basic, China) and using software Nextion editor (V0.53). Digital oscilloscope (Tektronix, USA) used to check the output. The measured TENS are Beurer (type EM49, SN 2019E17/0055803,
Germany), Intelect (NMES, USA), and BTL (type BTL-5000, SN 5001-0382931, USA).

\section{Experiment}

To experiment, the position of the red electrode cable must be higher than the black electrode cable. Because the red electrode is the anode, which is a positive terminal that positive current flows into the body, on the other hand, the black electrode is the cathode, which is a negative terminal that positive current then exits the body [16]. In this study, the author measures frequency and current at the sensor circuit output. The measured frequency is $10-200 \mathrm{~Hz}$, and the measured current is $0-80 \mathrm{~mA}$ - frequency measurement using three different TENS of brands that are BTL, Beurer, and Intelect. Current measurement only uses 1 TENS brand that is Beurer. In order to ensure the design is work according to its function, it needs to be checked using a standard device, in this case, using an oscilloscope.

\section{The Diagram Block}

The current-to-voltage and frequency-to-voltage circuits get input from a parallel TENS output. The output voltage from the current-to-voltage and frequency-to-voltage circuits is fed into Arduino and then converted again into current and frequency values. The conversion results next displayed on the Nextion TFT LCD in units of $\mathrm{mA}$ for current values and units of $\mathrm{Hz}$ for frequency values. On the Nextion TFT LCD, the output signal from TENS is also displayed (Fig. 1).

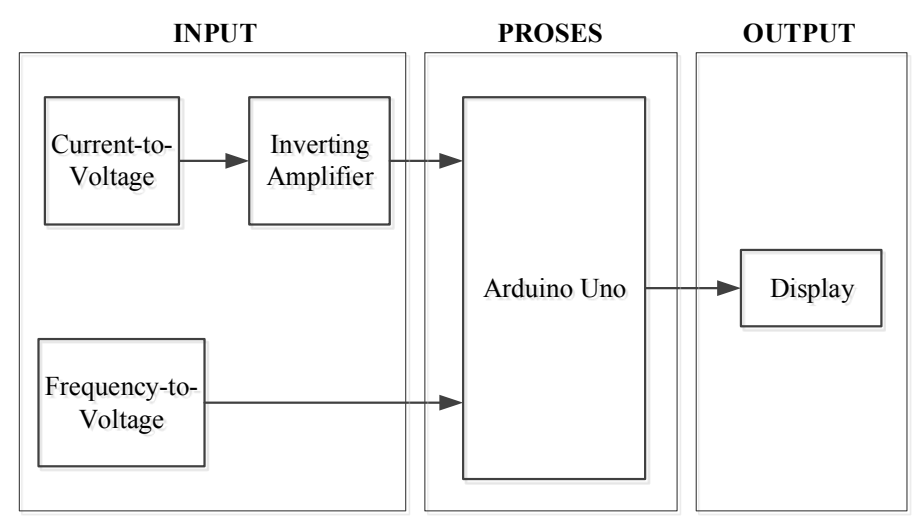

Fig 1. The diagram block

\section{E. The Flowchart}

When the power button pressed, the voltage gives input all the circuit, and the LCD will initialize. Before doing the measurements, first choose the parameter to be displayed (signal, frequency, or current). The Output of the TENS will go into the signal circuit, current-to-voltage, and frequency-tovoltage. The output of the circuit next processed on the Arduino and the result will be presented on the TFT LCD in $\mathrm{mA}$ for the current value and the $\mathrm{Hz}$ unit for the frequency 
value. In addition to the TFT LCD is also displayed the output signal from TENS (Fig. 2).

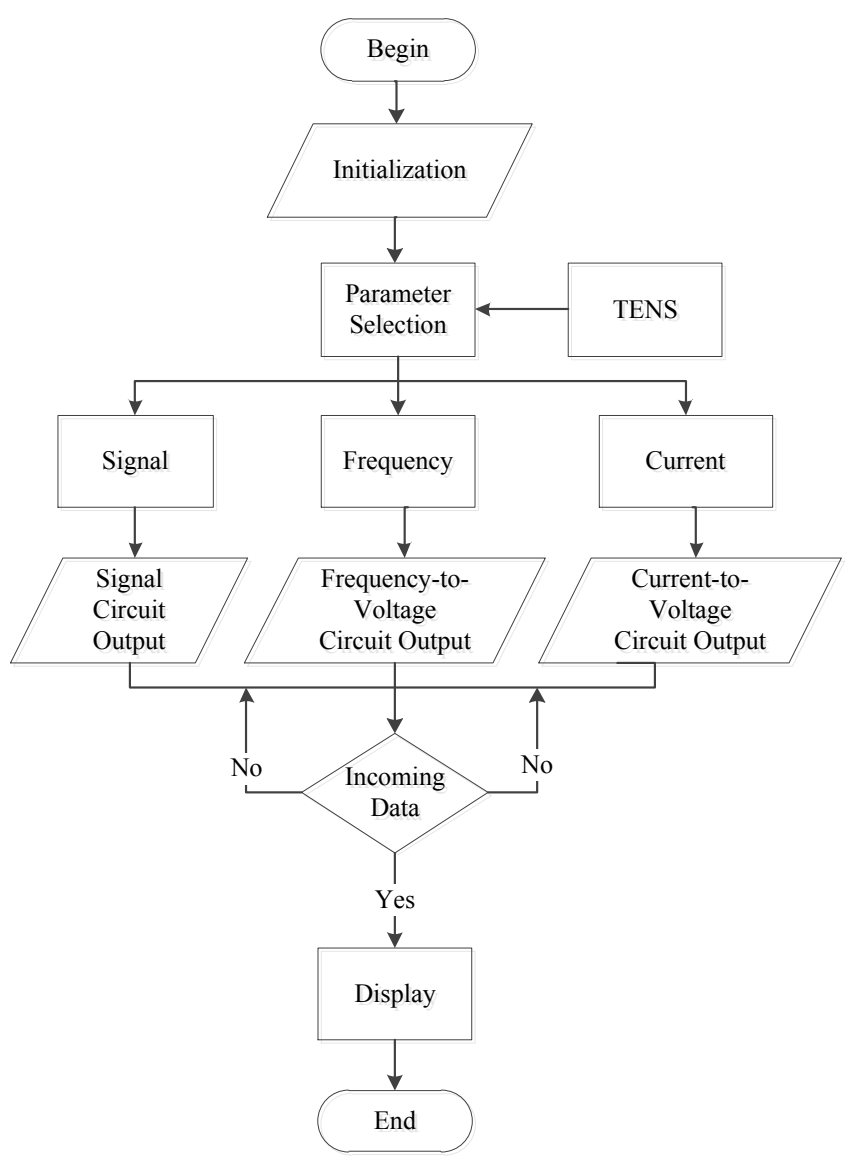

Fig 2. The Flowchart of the Arduino Program

\section{F. Circuit}

\section{1) Sensor Circuit}

The circuit uses a multiturn with a resistance of $1 \mathrm{~K} \Omega$. The resistance value has been adjusted to the amount of skin resistance under normal conditions (not too wet and not too dry). The output of this circuit then becomes the input for other circuits (Fig. 3).

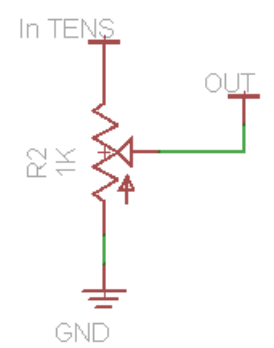

Fig 3. Sensor circuit

\section{2) Signal Circuit}

The voltage divider circuit serves to adjust the position of the signal on the display. An output voltage of this circuit then to be input to the summing amplifier circuit (Fig. 4).

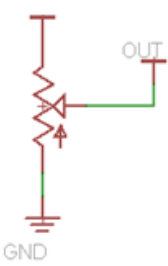

Fig 4. Voltage divider circuit

The summing amplifier is an Op-Amp used to two or more inputs into a single output voltage. The summing amplifier circuit gets input from a voltage divider circuit that uses a multiturn and a sensor circuit. The output of the summing amplifier circuit then becomes the input of the inverting amplifier circuit (Fig. 5).
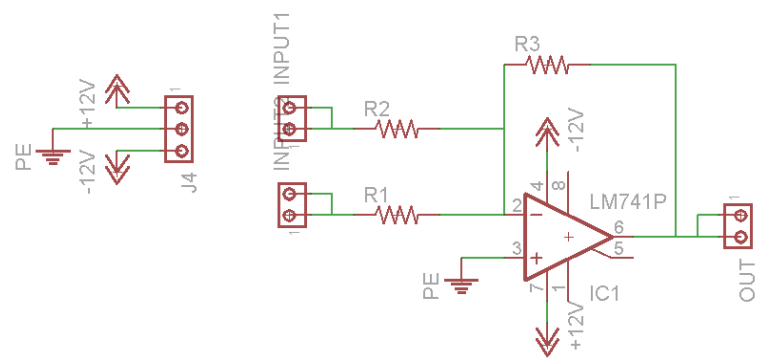

Fig 5. Summing amplifier circuit

The inverting amplifier is an Op-Amp which the output is given as feedback to the inverted terminal of input by means of a feedback resistor. This circuit gets input from summing amplifier. The inverting amplifier circuit uses $1 \mathrm{x}$ gain so it functions only to reverse the signal, then the output fed into Arduino (Fig. 6).
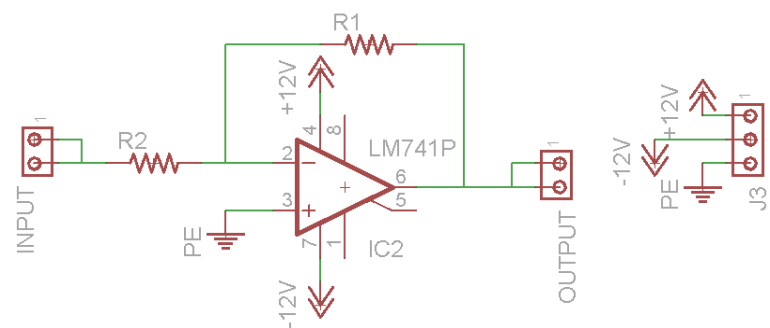

Fig 6. Inverting amplifier circuit 


\section{3) Frequency-to-Voltage Circuit}

The frequency-to-voltage circuit functions to convert frequencies into voltages (Fig. 7). This circuit uses IC LM2917, which has the advantage of being able to produce a voltage of 0 volts when a $0 \mathrm{~Hz}$ input frequency is given [17]. This circuit gets input from the sensor circuit. The output of this circuit then fed into Arduino.

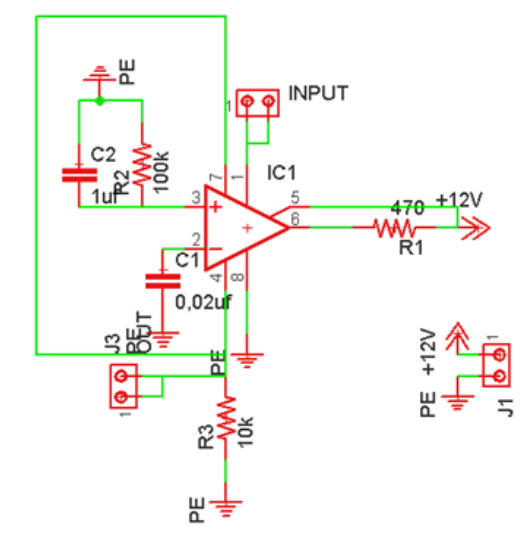

Fig 7. Frequency-to-Voltage circuit

\section{4) Current-to-Voltage Circuit}

The current-to-voltage circuit or trans-impedance amplifier using Op-Amp provides a time of conversion from current to voltage continuously (Fig. 8)

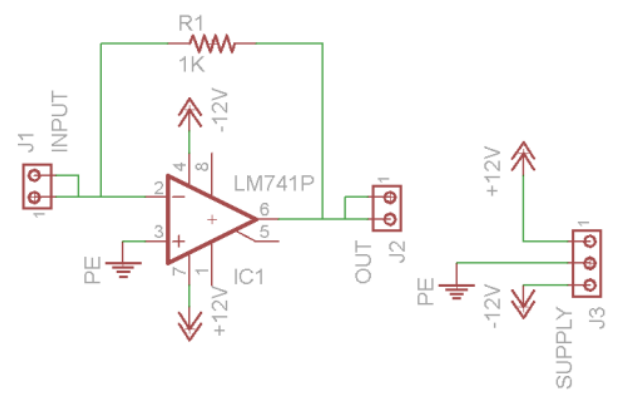

Fig 8. Current-to-Voltage circuit

[18]. This circuit gets input from the sensor circuit. The output of this circuit then fed into Arduino. The use of OpAmp in a current-to-voltage circuit can only be used to measure weak currents in the range of $\mathrm{pA}$ to $\mathrm{mA}$ [19].

\section{RESULTS}

In this study, the TENS measurement device was tested using a digital oscilloscope.

\section{A. TENS Measuring Device Design}

There are two banana plugs on the front side, and it has the function to connect TENS with a measuring instrument. Because all parameters cannot be displayed simultaneously, there are three toggles, each of which shows the parameters that the user wants to measure (signal, frequency, and current). This measuring instrument uses an Arduino Uno as a microcontroller, which has a voltage limit of 5 volts, so at the front side, there is also a toggle that has functions as a selector for measurements of more than 5 volts or less than 5 volts. The maximum voltage that can be measured is 10 volts (Fig. 9).

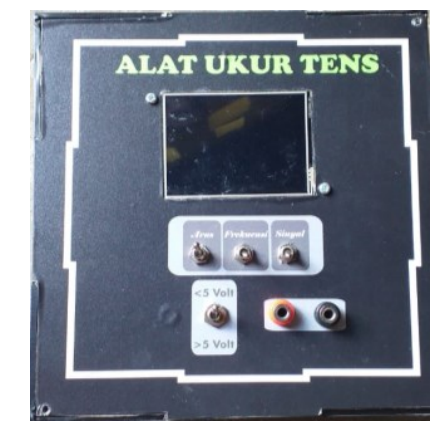

Fig 9. TENS Measuring Device design

The figure above is the result of the circuits and microcontrollers that every circuit connected by cable (Fig. 10).

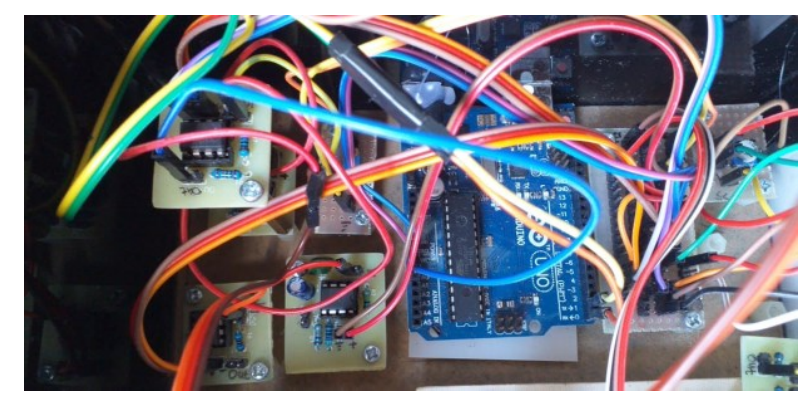

Fig 10. Results of microcontroller circuit design

The output signal circuit goes to Pin A0 Arduino, the frequency-to-voltage circuit goes to Pin A1 Arduino, and the current-to-voltage circuit goes to Pin A2 Arduino. RX Pin of Arduino is connected with TX Pin of Nextion; otherwise, the TX Pin of Arduino is connected with RX Pin of Nextion.

Pseudocode 1: :collecting the signal

INIT:

nexLoop(nex_listen_list)

\section{LOOP:}

int data $=\operatorname{map}(\operatorname{analogRead}(\mathrm{A} 0), 0,1024,0,255)$;

s0.addValue $(0$, CH0_OFFSET + data);

\section{ENDLOOP}


The signal enters pin A0 of Arduino from the output of the inverting amplifier circuit.

\section{Pseudocode 2: frequency counter}

LOOP:
float sensorValue $=$ analogRead(freq)/2.86;
IF (hold $<=$ sensorValue) THEN
hold=sensorValue;
ELSEIF (hold $>$ sensor) THEN
sensor=hold;
hold=0;
ENDELSEIF
int frekuensi = sensor;
Serial.print("n0frekuensi.val=");
Serial.print(frekuensi);
Serial.write(0xff);
Serial.write(0xff);
Serial.write(0xff);
ENDLOOP

Pin A1, initialized as freq, is a program for reading ADC data. Frequency $=$ freq / 2.86; is a program to convert ADC into frequency. Because some TENS devices have a patient safety mode, that at certain minutes TENS will automatically reduce the frequency, so the frequency program is given a hold that only reads the highest value. Therefore it is necessary to be given a reset button that must be pressed when measuring the frequency of the device whose value is lower than before.

Pseudocode 3: current reading

\section{LOOP:}

float arus $=\operatorname{analogRead}(\mathrm{A} 2) / 1024.0 * 5$;

IF (hold $<=$ arus) THEN

hold=arus;

\section{ENDIF}

ELSEIF (hold $>$ arusmax) THEN

arusmax=hold;

hold $=0$;

\section{ENDELSEIF}

unsigned int Ampere $=(\operatorname{arusmax} / 1000) * 1000 * 100$;

Serial.print("n1arus.val=");

Serial.print(Ampere);

Serial.write(0xff);

Serial.write(0xff);

Serial.write(0xff);

ENDLOOP

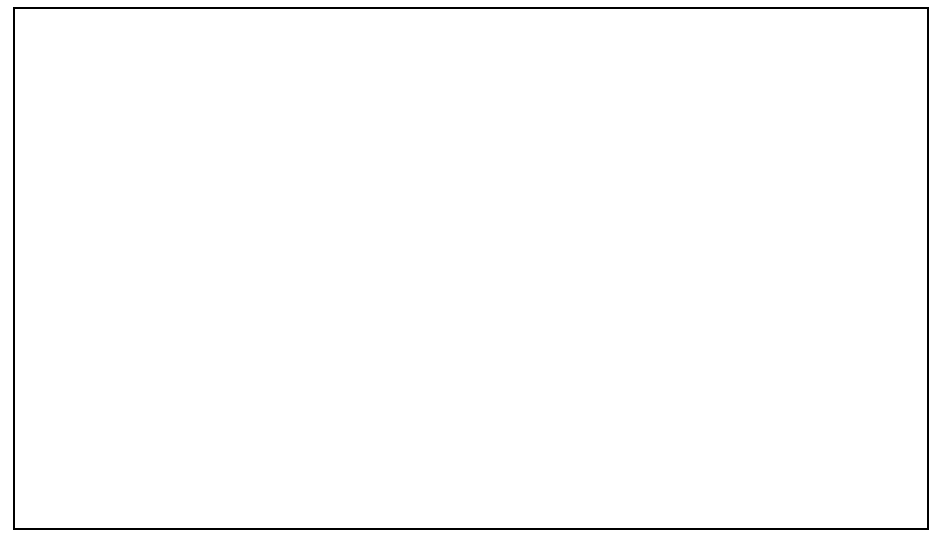

Pin A2, initialized as current, is a program for reading $\mathrm{ADC}$ data. Current $=$ current $/ 1024.0 * 5$; is a program to convert ADC into current.Because the TENS signal is sometimes above and sometimes below, the current program is given a hold that only reads the highest value. Therefore it is necessary to be given a reset button that must be pressed when measuring the frequency of the device whose value is lower than before.

\section{B. Measurement results}

TABLE I. TABLE OF FREQUENCY MEASUREMENT AND ERROR

\begin{tabular}{ccccccc}
\hline $\begin{array}{c}\text { Frequency } \\
(\mathbf{H z})\end{array}$ & Mean & SD & UA & UB & U95 & \%Error \\
\hline 10 & 8 & 1,4 & 0,8 & 0 & 3,44 & 0,2 \\
20 & 17 & 2,1 & 1,2 & 0 & 5,16 & 0,15 \\
30 & 28 & 1,4 & 0,8 & 0 & 3,44 & 0,07 \\
40 & 38 & 1,4 & 0,8 & 0 & 3,44 & 0,05 \\
50 & 48 & 1,4 & 0,8 & 0 & 3,44 & 0,04 \\
60 & 59 & 0,7 & 0,4 & 0 & 1,72 & 0,02 \\
70 & 68 & 1,4 & 0,8 & 0 & 3,44 & 0,03 \\
80 & 82 & 1,4 & 0,8 & 0 & 3,44 & $-0,25$ \\
90 & 89 & 0,7 & 0,4 & 0 & 1,72 & 0,01 \\
100 & 101 & 0,7 & 0,4 & 0 & 1,72 & $-0,01$ \\
110 & 109 & 0,7 & 0,4 & 0 & 1,72 & 0,01 \\
120 & 119 & 0,7 & 0,4 & 0 & 1,72 & 0,01 \\
130 & 130 & 0 & 0 & 0 & 0 & 0 \\
140 & 136 & 2,8 & 1,6 & 0 & 6,88 & 0,03 \\
150 & 148 & 1,4 & 0,8 & 0 & 3,44 & 0,01 \\
160 & 160 & 0 & 0 & 0 & 0 & 0 \\
170 & 171 & 0,7 & 0,4 & 0 & 1,72 & $-0,01$ \\
180 & 182 & 1,4 & 0,8 & 0 & 3,44 & $-0,01$ \\
190 & 191 & 0,7 & 0,4 & 0 & 1,72 & $-0,01$ \\
200 & 197 & 2,1 & 1,2 & 0 & 5,16 & 0,02 \\
\hline
\end{tabular}

Note: UB has a value of 0 because the writer has not taken measurements using a comparative measurement tool.

From the results of the calculation data in Table I, we get the appropriate average values and standard deviations (SD), UA, UB, U95, and error values for frequency measurement.

TABLE II. TABLE OF CURRENT MEASUREMENT AND ERROR

\begin{tabular}{ccccccc}
\hline $\begin{array}{c}\text { Current } \\
(\mathbf{m A})\end{array}$ & Mean & SD & UA & UB & U95 & \%Error \\
\hline 0,672 & 0,24 & 0,19 & 0,08 & 0 & 0,21 & 0,64 \\
2,4 & 1,5 & 0,37 & 0,14 & 0 & 0,336 & 0,38
\end{tabular}




$\begin{array}{ccccccc}3,76 & 3,3 & 0,19 & 0,07 & 0 & 0,17 & 0,12 \\ 6,32 & 5,1 & 0,5 & 0,19 & 0 & 0,47 & 0,19 \\ 6,64 & 6,4 & 0,1 & 0,04 & 0 & 0,096 & 0,04 \\ 9 & 7,95 & 0,43 & 0,16 & 0 & 0,392 & 0,12\end{array}$

Note: UB has a value of 0 because the writer has not taken measurements using a comparative measurement tool.

From the results of the calculation data in Table II, we get the appropriate average values and standard deviations (SD), UA, UB, U95, and error values for current measurement.

\section{DISCUSSION}

Based on data retrieval from the TENS device, it can be seen that the frequency measurement between the module and the settings on the equipment is in the tolerance of $\pm 10 \%$ with the largest error of $0.2 \%$. In previous studies, the research using high-speed comparator chip TL3016 to detect the signal source and using C8051F020 as the control module did not yet have many references. Data retrieval for current is done once because not all TENS devices have a current set that is equipped with a current intensity value. Based on these data, the current measurement between the design and the settings is in the tolerance $\pm 10 \%$. However, when setting the current in step 1 . The largest error is $0.64 \%$. In previous studies, it can be known that the appliance was not good if used to measure electrical current under $10 \mathrm{~mA}$. However, it is better if we used to measure electrical current above $10 \mathrm{~mA}$, and the other studies can only measure current with a measuring limit of 50 $\mu \mathrm{A} ; 2.5 \mathrm{~mA} ; 25 \mathrm{~mA}$; and $0.25 \mathrm{~A}$. In practical, this measuring device leads to more simple when calibrating TENS.

\section{CONCLUSION}

This study can be presented TENS Measuring Device using low-cost materials and have high accuracy in frequency and current measurement; however, the signal displayed is less accurate when compared to the oscilloscope. This research still needs to be developed in the generator signal unit so that the size is more compact.

\section{REFERENCES}

[1] S. N. Gozani and X. Kong, "Real-World Evidence for the Widespread Effects of Fixed-Site High- Frequency Transcutaneous Electrical Nerve Stimulation in Chronic Pain," Journal of Pain \& Relief , vol. 7, no. 4, 2018.

[2] K. Osteoarthritis et al., "Which is the Appropriate Frequency of TENS in Managing Knee Osteoarthritis: High or Low Frequency? Diz Osteoartriti Tedavisinde Hangi TENS", Frekans1 daha Uygundur: Yüksek veya Düşük Frekans, vol. 7, no. 3, pp. 339-344, 2016.

[3] L. Santos et al., "Transcutaneous electrical nerve stimulation ( TENS ) reduces pain and postpones the need for pharmacological analgesia during labour: a randomised trial," J. Physiother., vol. 62, no. 1, pp. 2934, 2016.

[4] C. G. T. Vance, D. L. Dailey, B. A. Rakel, and K. A. Sluka, "Using TENS for pain control: the state of the evidence," Pain management vol. 4, pp. 197-209, 2014.
[5] A. Universityharyana, "Use of Transcutaneous Nerve Stimulator ( TENS ) for localized Pain relief - A REVIEW,", Trends Comput. Commun No. May, pp. 707-710, 2017.

[6] R. M. Fish and L. A. Geddes, "Conduction of Electrical Current to and Through the Human Body: A Review," Eplasty, pp. 407-421, 2009.

[7] G. N. Reddy and G. J. U. Reddy, "Effects of Wireless Electricity on Human Bodies,", International Journal of Engineering Trends and Technology,(IJETT), vol. 4, no. 6, pp. 2567-2569, 2013.

[8] C. Mj, W. Gibson, W. Bm, C. Meads, and O. C. Ne, "Transcutaneous Electrical Nerve Stimulation ( TENS ) for chronic pain - an overview of Cochrane reviews ( Protocol ),", Cochrane Database of Systematic Reviews, no. 9, 2015.

[9] E. Bravo-esteban, J. Go, and J. Taylor, "Intensity matters: Therapistdependent dose of spinal transcutaneous electrical nerve stimulation,", PLoS One, pp. 1-15, 2017.

[10] G. L. Y. Cheing, A. Y. Y. Tsui, S. K. Lo, and C. W. Y. Hui-chan, "Optimal Stimulation Duration Of Tens In The Management Of Osteoarthritic Knee Pain,", Journal of rehabilitation medicine, no. 14, pp. 62-68, 2003.

[11] J. A. Prakosa, "Prototipe Frekuensi Meter Rentang Ukur ( $10 \sim 2000$ ) $\mathrm{Hz}$ Terkalibrasi ke Standar Primer Frekuensi Prototype of Meter Frequency Range $(10 \sim 2000) \mathrm{Hz}$ Calibrated to Primary Standard Frequency,", Jurnal Elektra, vol. 9, no. 1, pp. 11-20, 2015.

[12] L. Su, A. Shang, J. Qin, and J. Yang, "Design and Implementation of High Precision Digital Frequency Meter Based on C8051F020 Microcontroller Signal source C8051F020," 2017 2nd Joint International Information Technology, Mechanical and Electronic Engineering Conference (JIMEC 2017). Atlantis Press.

[13] A. Adhiem, E. Rahmawati, J. Fisika, and U. N. Surabaya, "Rancang Bangun Amperemeter Digital Berbasis Metode Induksi Elektromagnetik,", Inovasi Fisika Indonesia , vol. 07, pp. 36-41, 2018.

[14] Y. Kabalci, "The Low Cost Voltage and Current Measurement Device Design for Power Converters," 2016.

[15] B. P. Sembodo, A. Meter, D. C. Menggunakan, S. Interface, P. Central, and P. Unit, "Ampere Meter Dc Menggunakan Adc 0804 Sebagai Interface Pada Central Processing Unit ( Cpu ) Komputer,", WAKTU, vol. 09, pp. 8-14, 2011.

[16] A. F. Dasilva, M. S. Volz, M. Bikson, and F. Fregni, "Electrode Positioning and Montage in Transcranial Direct Current Stimulation,", JoVE (Journal of Visualized Experiments), no. May, 2011.

[17] D. Information, "LM2907 and LM2917 Frequency to Voltage Converter PACKAGE," no. 1, 2016.

[18] K. Gupta, P. B. P. Singh, and R. Choudhary, "Design and Analysis of Current-to-Voltage and Voltage - to-Current Converters using $0.35 \mu \mathrm{m}$ technology,", technology,vol. 2, no. 4, pp. 3-7, 2012.

[19] P. Protiva, "Low-cost current-to-voltage converter for DC measurements in a wide dynamic range Pavel Protiva," pp. 22-25, 2008. 